\title{
"Doctor my eyes": A natural experiment on the demand for eye care services
}

\author{
H. Dickey ${ }^{1}$, D. Ikenwilo ${ }^{2}$, P. Norwood ${ }^{2}$, V. Watson ${ }^{2}$, and A. Zangelidis ${ }^{1, *}$ \\ 1: Centre for European Labour Market Research (CELMR), Business School, University of Aberdeen, Scotland \\ 2: Health Economics Research Unit, University of Aberdeen, Scotland \\ *: Corresponding author. Email: a.zangelidis@abdn.ac.uk Telephone: +44(0)1224 273122
}

\{The paper is accepted for publication in the journal of Social Science and Medicine\}

December 2015

\begin{abstract}
:
Preventive health care is promoted by many organisations from the World Health Organisation (WHO) to regional and national governments. The degree of cost-sharing between individuals and the health care service affects preventive service use. For instance, out-of-pocket fees that are paid by individuals for curative services reduce preventive care demand. We examine the impact of subsidised preventive care on demand. We motivate our analysis with a theoretical model of inter-temporal substitution in which individuals decide whether to have a health examination in period one and consequently whether to be treated if required in period two. We derive four testable hypotheses. We test these using the subsidised eye care policy introduced in Scotland in 2006. This provides a natural experiment that allows us to identify the effect of the policy on the demand for eye examinations. We also explore socio-economic differences in the response to the policy. The analysis is based on a sample from the British Household Panel Survey of 52,613 observations of people, aged between 16 and 59 years, living in England and Scotland for the period 2001-2008. Using the difference-in-difference methodology, we find that on average the policy did not affect demand for eye examinations. We find that demand for eye examinations only increased among high income households, and consequently, inequalities in eye-care services demand have widened in Scotland since the introduction of the policy.
\end{abstract}

Keywords: UK, Scotland, Preventive care, subsidised care, eye examinations, natural experiment

\section{Acknowledgements:}

This paper is dedicated to our friend Divine Ikenwilo, who passed away on the 27 th November 2015. Divine was a gifted researcher who was taken from us too early and will be sorely missed by everyone in the team. Our thoughts are with his family. This research was funded by a research grant (CGZ/2/533) from the Chief Scientist Office of the Scottish Government. The Health Economics Research Unit is funded by the Scottish Government Health and Social Care Directorate. The usual disclaimer applies. 


\section{Introduction}

Preventive health care is promoted by many organisations from the World Health Organisation (WHO) to regional and national governments. Preventive care can detect illnesses earlier, making them easier to treat or reducing mortality. The Grossman model (1972) provides a theory of the demand for health, but the model does not include uncertainty and this makes it difficult to distinguish between the demand for preventive and curative care (Kenkel, 1994). Okeke et al., (2013) propose a theory of demand for preventive care and (possible) subsequent treatment and apply this to study screening demand in Nigeria.

Many preventive care services require individuals to pay an out of pocket user fee. User fees are a positive price charged by providers to users at the point of delivery. Economically, the rationale for user fees is to improve allocative efficiency and act as a revenue collection mechanism (Stabile and Thomson, 2014). Existing empirical evidence indicates that the degree of cost-sharing influences the use of preventive services; in particular, that out-of-pocket fees borne by individuals reduce the demand for preventive care (e.g. cancer screening, vaccinations, etc.) by increasing the price paid by the individual at the time of consumption. The overwhelming majority of studies conducted in developed countries conclude that cost-sharing reduces demand for preventive services (Christensen, 1995; Friedman et al., 2002; Kiefe et al., 1994; Krůtilová, 2010; Lundberg et al.,1998; Nexøe et al., 1997; Solanki et al., 2000; Stoner et al.,1998). Similarly, for studies conducted in low- and middle-income countries (LMICs), the evidence suggests that the introduction or increase in user fees has almost and everywhere led to a decrease in utilisation (Schokkaert and Van de Voorde, 2011; Cohn and Dupas, 2010; Borghi et al., 2006; Souteyrand et al., 2008)

Economic theory further predicts that cost-sharing generates adverse distributional consequences as low income individuals reduce utilisation more than the remaining population. Most empirical studies find that user fees lead to a stronger reduction in utilisation among the poor (James et al., 2006) in both developed countries (Thomson et al., 2003) and LMICs (Sepehri and Chernomas, 2001). Thus, user fees threaten equality of access as poorer individuals may not always seek appropriate care or postpone necessary health care consumption.

Most studies focus on the cost of preventive care and its effect on demand, and ignore costs that arise from treatment required after screening. Okeke et al., (2013) provide a novel contribution by examining the impact of subsidising treatment costs on the demand for cancer screening in Nigeria. We further add to the literature by investigating how the removal of an out-

of-pocket fee for eye tests influences the demand for testing when follow-up treatment costs are not covered and are borne by individuals.

This study contributes to the literature on demand for preventive care by exploring the effect on demand of subsidising preventive care to make it free at the point of delivery. We study the impact of subsidising preventive care in the context of demand for eye care services in Scotland. In 2006, the Scottish Government introduced a subsidised eye examination policy that provided examinations at private optometrists at no out of pocket cost to all individuals who are resident in Scotland. Previously, Scotland and the rest of the United Kingdom (UK) had the same eye care service, in which individuals paid for eye tests out of pocket at a private optometrist. In this paper, we examine the effect of the policy change in Scotland using difference in difference 
methods in which Scotland is the treated group and England is used as the control group. Our analysis provides empirical evidence about the determinants of preventive care demand.

The paper makes three contributions to the literature. First, we examine the issue of subsidising preventive care within a natural experiment framework. The subsidisation of eye examinations in Scotland is a transparent exogenous source of variation in the cost of preventive care that enables us to identify the control and treatment groups and explore the policy effect on the demand for eye examinations, using suitable econometric techniques on a large populationrepresentative sample. The majority of studies in the preventive care literature either offer qualitative evidence or employ simple statistical analysis using small-size data sets (as discussed in Okeke et al., 2013). We find that on average the policy had no effect on the demand for eye examinations. Second, we explore how people of different socioeconomic status responded to the policy. We find that only higher income individuals increased their demand for eye examinations. This analysis provides useful information for policy makers and highlights how the policy has affected inequality in health care use. Third, we contribute to the wider debate about the benefits of universal subsidised health care when public spending is reduced. The remainder of the paper is organised as follows: in section 2 we present a theoretical model and derive testable hypotheses for our empirical analysis, in section 3 we discuss the natural experiment based on the eye examinations subsidy policy in Scotland and the data used in the empirical analysis, in section 4 we present our empirical analysis and in section 5 we conclude.

\section{Theoretical framework}

We model individuals' decisions to have a health examination using an inter-temporal choice framework (Okeke et al., 2013). The demand for health examinations is driven by individuals' demand to acquire information about their health status that may be useful for the detection and treatment of health conditions. The demand for health testing differs from the demand for health care. At the time of the decision to undergo an examination, the individual has an expectation about his/her health state, but does not have full information. Therefore, the individual is uncertain about the future benefit of the information they will receive from the examination.

We assume a two period model in which individuals derive utility from health and consumption. There are two health states "good health" and "bad health" with probability of each state being $1-p$ and $p$, respectively. In period one, the individual decides whether to have an examination or not. Depending on the outcome of the examination, the individual will undergo a treatment or not in period two. Without loss of generality, we can also assume that in period 1 all individuals have good health. The decision to have an examination involves some cost $(c)$ that reflects both the financial cost and opportunity cost of time. The latter is important, because even if an examination is fully-subsidised individuals would still have to consider the time price of attending and "consuming" health care. Traditionally the opportunity cost of time is measured either as forgone labour income, if time is taken from paid employment, or cost of leisure time, if time is taken from non-labour time (Cauley, 1987; Janssen, 1992; Torgerson et al., 1994). A priori, it is not clear whether it is the people at the top of the income distribution or those at the lower part of the income distribution who are expected to have a higher opportunity cost of time. In relation to forgone earnings, individuals who are salaried workers should not face 
a wage reduction when attending for health care. However, hourly-paid workers and piece workers would lose labour-income. Therefore, one could hypothesise that the lower socioeconomic groups potentially face a higher opportunity cost since they are more likely to be hourly paid or piece workers. One could come to the opposite conclusion when considering leisure time. The price of leisure time is the wage rate that people forgo by not offering to work. Hence, the opportunity cost of time should be higher for those high in the income distribution, since their leisure time costs more. In the paper, for the purpose of our analysis we acknowledge that there is an opportunity cost of time associated with attending health care, but do not make any further assumptions regarding its relative size between high and low socio-economic groups. When the examination predicts the bad health state in period two, the individual undergoes a treatment that also incurs some cost $(s)$. Treatment is assumed to restore individuals' health to the good state.

To derive testable hypotheses, we assume that individuals have a utility function characterised by constant relative risk aversion and a risk aversion parameter equal to 1, so we assume a logarithmic functional form for the utility function. Following the tradition of state-dependent utility (Zeckhauser, 1970 and 1973; Arrow, 1974; and Viscusi and Evans, 1990), we introduce a multiplicative parameter for the individual's health status $(u$ for good health state and $v$ for bad health state). The logarithmic utility function is expressed as $u[\log (Y)]$ for good health state and $v[\log (Y)]$ for bad health state, where $Y$ represents level of income. If we further assume that utility and the marginal utility of consumption are greater when the person is in a good health state, an assumption widely considered in the literature (Viscusi and Evans, 1990), then $u>v$.

Our framework can then be described as follows:

\section{Person has health examination in period 1}

In period 1: $\quad U=u \log (Y-c)$

In period 2: $\quad U=p(\max [u \log (Y-s), v \log (Y)])+(1-p) u \log (Y)$

\section{Person does not have health examination in period 1}

In period 1: $\quad U=\operatorname{ulog}(Y)$

In period 2: $\quad U=\operatorname{pvlog}(Y)+(1-p) u \log (Y)$

Figure 1 provides a graphical representation of the two decisions to (i) undertake a health examination and (ii) receive treatment in a sequential two-period framework. We assume that the cost of treatment and the associated loss of consumption is smaller than the utility loss due to having bad health $u \log (Y-s)>v \log (Y)$. This implies that all individuals whose examination predicts bad health will have treatment in period 2. We assume that the cost of examination and the cost of treatment are both smaller than individual's income, $Y-s>0$ and $Y-c>0$.

The individual will be indifferent between having an examination or not at some critical level of $p^{*}$ where:

$$
\begin{array}{r}
u \log (Y-c)+p^{*} u \log (Y-s)+\left(1-p^{*}\right) u \log (Y)= \\
u \log (Y)+p^{*} \operatorname{vlog}(Y)+\left(1-p^{*}\right) u \log (Y)
\end{array}
$$


which implies

$$
p^{*}=\frac{u[\log (Y)-\log (Y-c)]}{u \log (Y-s)-v \log (Y)}
$$

$p^{*}$ may be interpreted as the individual's threshold level of bad health - the level of bad health at which the individual is indifferent between having an examination and not having one - and thus defines a utility maximizing decision rule. Individuals will take a health examination only when $p \geq p^{*}$.

The model allows us to derive some interesting predictions regarding the level of the threshold, $p^{*}$. First, we can easily see that the cost of examination $(c)$ is positively associated with $p^{*}$, since $\frac{\partial p^{*}}{\partial c}>0$. This implies that as the cost of the examination reduces, the threshold level reduces as well, so more people choose to have an examination. Second, as the cost of treatment $(s)$ increases, the threshold level increases and fewer people are willing to undertake an examination, , since $\frac{\partial p^{*}}{\partial s}>0$. Third, the model allows us to hypothesise how socio-economic differences amongst individuals will affect the uptake of the examination. In particular, the model suggests that individuals with higher incomes will have a lower $p^{*}$ threshold. It becomes clear then that a priori we should expect higher levels of examinations from the higher socio-economic groups, since $\frac{\partial p^{*}}{\partial Y}<0$. All mathematical derivations are provided in the Appendix.

We use this model to examine the demand for eye examinations. Prior to testing their eyes individuals have an expectation about the state of their eye health that is analogous to the probability of bad health $(p)$. The threshold level of having an eye examination $p^{*}$ depends on the cost of the examination $(c)$ and the cost of treatment $(s)$, which can be thought of as the relative cost of spectacles or other eye-care related products that the individual may purchase. The predictions of the model can be summarised as follows:

- Hypothesis 1: A reduction in the cost of the examination will lead to an overall higher demand for testing;

- Hypothesis 2: People who overall perceive themselves to have better (eye) health, lower $(p)$, will be less likely to take an examination;

- Hypothesis 3: People from higher socio-economic groups will have a higher uptake of examinations.

\section{A natural experiment on the demand for eye examinations}

Eye care services in Scotland changed on the 1st April 2006. The Scottish Government introduced free biennial NHS eye examinations. The policy aimed to increase demand for eye examinations and in doing so to improve the visual health of its population through the early detection of eye health problems (Scottish Executive, 2005). Until 2006 all UK countries had the same eye care policy, namely, that most people who wanted or needed an eye test would pay for this out of pocket at a private optometrist. A number of groups were exempt from paying for an 
eye test. These were: under 16 or over 60 years old; full-time students aged 16-18; those claiming income support or income-based job seekers allowance; those entitled to an NHS Tax Credit Exemption Certificate, pension credit guarantee credit; those registered as blind or partially sighted; diagnosed with glaucoma; at risk of glaucoma; diagnosed with diabetes; and those with an HC2 or HC3 Certificate. Data available from the Information Services Division (ISD) of NHS Scotland shows that on average $9 \%$ of the Scottish population are exempt for paying for eye care services (based on voucher type 3, which included the provision of glasses and contact lenses). This proportion has remained stable (at 9\%) from 2006/07 to 2013/14. After 2006, in Scotland, some groups are entitled to more frequent free eye examinations based on their experience or risk of eye related conditions. Patients under 16 years, or aged 60 years or over; individuals with glaucoma, or those aged 40 years or over with a close family history of glaucoma; and patients with ocular hypertension or with diabetes are entitled to a free eye examination every year. For all other patients, aged between 16 years and 59 years, the prescribed frequency of an eye examination is every two years.

These policy changes in Scotland provide a natural experiment. The policy introduced an exogenous variation in the cost of eye examinations that affected only Scotland. Thus we can identify a treatment group (Scotland) and a control group (England) that enables us to empirically assess the treatment/policy impact on the demand for eye examinations and explore socioeconomic differences in how people responded to the policy.

\subsection{Data}

We use the British Household Panel Survey (BHPS) dataset to assess the impact that the free eye examination policy had on the Scottish population. The BHPS is a nationally representative annual survey of adults, covering over 5,000 households in the UK from 1991-2008 (Taylor et al., 2010). Ethics approval is not required for this paper because the BHPS is an anonymised data set available in the public domain. Our sample consists of people aged between 16 and 59 years living in England and Scotland for the period of time 2001-2008. The advantages of this survey are that: (i) it is a UK representative sample; (ii) it is conducted at an individual-level; (iii) it contains rich information on the socio-economic and demographic characteristics of the respondents; and (iv) it has been running for a sufficiently long period of time to allow us to observe individuals' choices before and after the policy.

Our analysis, based on the BHPS, focuses on people's responses to a specific question in the BHPS on whether they had an eye test since September 1st in the previous year. In order to identify the free eye care policy period in Scotland we look at the survey interviews conducted since 2007 as they refer to eye examinations that took place from September 2006 onwards, after the policy was introduced (April 2006). For the interviews that took place between April and December in the year 2006, we cannot identify whether individuals in Scotland had a fee-free eye examination or not since the eye-testing period covered (between September 2005 and the time of the interview) includes both a pre and post policy period. Therefore, we exclude the observations that fall in this period of time. As a result, the sample considered in 2006 is significantly smaller than the other years, with only 210 observations from England and 176 observations from Scotland included. 
Attrition rates between BHPS waves are relatively low. Taylor (1994) reported specifically on attrition in the early waves of the BHPS, suggesting it to be empirically less of a concern that in some other longitudinal designs. The dataset used in the analysis is unweighted. As discussed in Dickens (1990) and Solon et al., (2015), there is no automatic gain in efficiency from using weights. Furthermore, Lambert (2006) argues that multivariate analyses of relative effects are robust to smaller sampling imperfections, hence it would not be unreasonable to use unweighted samples of the BHPS.

The BHPS also collects a wide range of demographic and socio-economic characteristics of the respondents. Table 1 provides the definitions of the variables used in the analysis and Table 2 presents some descriptive statistics on the whole sample and by eye examination status. Out of the original 56,239 sample observations, information on eye tests was missing in 3,626 cases leaving a sample of 52,613 observations. For the individuals whose information on eye tests was missing in at least one wave of the BHPS, average eye examination uptake is 0.351 , whereas the uptake is marginally higher (0.364) for those who had no missing information. However, the difference in means is not statistically significant at the $5 \%$ level, which provides some assurance regarding potential selection issues. Overall, around one third of the sample had an eye examination. As expected, a larger proportion of women have their eyes examined compared to men: this is consistent with the frequently reported result that health services demand is higher amongst women than amongst men (Vaidya et al., 2012; Redondo-Sendino et al., 2006; Bertakis et al., 2000). A higher proportion of individuals aged between 40 and 59 years have had an eye examination, whereas eye care demand is lower amongst the younger age groups. This is in line with the argument that health risk increases with age and so should health care consumption (e.g. Kenkel, 1994). A lower proportion of individuals reporting good health have eye examinations and a higher proportion of higher educated individuals have eye examinations. These findings are consistent with the predictions of the Grossman model and also consistent with results from other empirical research (Carrieri and Bilger, 2013; Kenkel, 1994).

\section{Empirical Analysis}

\subsection{Demand for eye-care in Scotland}

To assess how individuals responded to the free eye examination policy we use the differencein-difference (DD) estimation method to examine the policy's impact while isolating the effects of confounding factors at the time of the policy's introduction. The DD method has been used to test the impact of policy and/or health system interventions on health care demand in other settings (Layte et al., 2009; Chatterji and Meara, 2010; Basinga et al., 2011; Ikenwilo, 2013). We consider two groups of individuals; those affected by the policy (Scotland - treatment group), and those unaffected by the policy (England - control group). The selection of the control group is important because use of the DD method assumes that the outcome (eye examinations) in the treatment and control groups would have followed a common trend in the absence of the policy (free eye examinations), and therefore it is the policy that causes deviation from this common trend. This assumption is difficult to test. Figure 2 plots the average proportion of the population having an eye examination for England and Scotland before and after the policy to provide an 
informal graphic test of the common trend assumption and offer some support that the underlying trends were similar in the pre-policy period. The spike in the eye examination uptake recorded in 2006 is probably driven by the small sample size used in that particular year, so the 2006 figures should be interpreted with caution. Although, this may cast doubt on the validity of the numbers presented for the year 2006, the purpose of Figure 2 is to provide a visual confirmation of the common trend assumption between England and Scotland for the year prior to the policy.

Placebo (falsification) tests presented in Section 5.3 lend further support to the common trend assumption and the selection of England as the control group. Wales and Northern Ireland were also considered as control groups, but there was not a common trend in eye examinations.

We are interested in eye-care demand for group $i$, where $i=0$ for the control group and $i=1$ for the treatment group, at time $t$, where $t=0$ before the policy and $t=1$ after the policy change. The DD estimator is the difference in the means of the demand rate between the treatment and control groups between both time periods:

$$
\Delta y_{i}=\beta_{0}+\beta_{1} F_{i}+\varepsilon_{i}
$$

in which

$$
\Delta y_{i}=y_{i 1}-y_{i 0}
$$

In the regression analysis framework, the dependent variable $y_{i}$ indicates that individual $i$ has an eye test, and $F_{i}$ defines the individuals in the treatment group. Equation (7) assumes differences in demand rates between treatment and control groups are attributable to the policy and is identified only by using the same individuals in both groups. When the data do not contain the same individuals in both groups, a multiple variable regression containing at least three regressors (those affected by the policy, the time period following the policy and the impact of the policy) is estimated:

$$
y_{i}=\beta_{0}+\beta_{1} F_{i}+\beta_{2} A_{i}+\beta_{3} F_{i} \cdot A_{i}+\varepsilon_{i}
$$

Equation (9) captures possible differences between those individuals who are affected by the policy and those who are not. $A_{i}$ is a dummy variable indicating the time period after the introduction of the policy; $\beta_{1}$ is a measure of the difference in eye tests between the treatment and control groups prior to the policy; $\beta_{2}$ is a measure of aggregate factors that cause changes in eye tests irrespective of the policy; $\beta_{3}$ is a measure of the effect of the free eye-care policy on demand in Scotland, holding all other confounding factors constant; $\varepsilon_{i}$ is the error term, while $\beta_{0}$ is the usual intercept.

The dependent variable is a binary variable that takes the value of one if the respondent had an eye examination since September last year and zero otherwise. We begin with a parsimonious specification (1), as described in equation (9), which includes only a control for people living in Scotland (treatment group), a dummy variable indicating the policy period (defined by the interviews that took place from 2007 onwards), and their interaction term. As explained above, the main estimated parameter of interest is the coefficient of the interaction term that provides a measurement of the effect of free eye examinations on eye-care demand levels in Scotland. For 
robustness purposes, we also consider a set of additional covariates. The full specification model includes a control variable for those individuals who may be entitled to a free eye examination based on their socio-economic or health characteristics. This is a group of individuals who would normally receive free eye examinations in both England and Scotland in all years covered in the sample (before and after the policy). Furthermore, individuals who have their eyes tested may be more likely to have regular eye examinations. For the majority of individuals, the NHS recommends that they have eye examinations every two years, while for the more vulnerable groups (e.g. over 60 years, those diagnosed with diabetes or glaucoma, etc.) the recommendation is every year. Therefore, in order to control for state dependency we also include lagged values of the dependent variable for the periods $\mathrm{t}-1$ and $\mathrm{t}-2$. This unavoidably leads to a reduction in the sample size, since for many individuals the number of years that can be used in the analysis reduces. The presence of children in the household may affect the lifestyle and health related choices people make. This is the reason why the number of children, along with other controls for household and individual characteristics such as gender, age, marital status, and education, are included in the specification. Finally, two dummy variables for individuals whose equivalised household income is either in the top or bottom $25 \%$ of the income distribution and year trends are also considered.

The eye-examination equations are estimated using a linear probability estimator with robust standard errors, clustered by individuals, and presented in Table 3. The estimated coefficient of the interaction term (Scotland $\times$ Policy), in both specifications explored, has a positive sign but it is statistically insignificant. This does not provide supporting evidence for Hypothesis 1: that a reduction in the cost of the examination will lead to an overall higher demand for testing. We find that the policy did not have a statistically significant effect on demand for eye examinations in Scotland.

The results from the full specification model that includes demographic and socioeconomic differences provide support for both Hypothesis 2: that people who overall perceive themselves to have better (eye) health, lower ( $p$ ), will be less likely to take an examination; and Hypothesis 3: that people from higher socio-economic groups will have a higher uptake of examinations. Individuals who reported good overall health and people who had no visits to their GP in the past 12 months are less likely to have an eye examination (1.3\% and 3.6\% less likely, respectively). Individuals who perceive themselves to be in a good health state are less likely to have an eye examination because their probability of bad health $(p)$ is below their threshold level $p^{*}$. The effect related to GP visits may also be driven by the fact that people who visit their GP may be referred for an eye examination, thus may be more likely to have an eye examination than those who did not visit their GP. Individuals from wealthier households (top $25 \%$ of the income distribution) are found to be $1.4 \%$ more likely to have an eye examination, compared to those in the middle of the income distribution (25-75\%), whereas the opposite is true for those located in the bottom $25 \%$ of the distribution. Education increases the demand for eye examinations.

We also find that demand for eye examinations is higher among older people, women, people who are married, living together or those separated than younger people, men or single people, respectively. 


\subsection{Socio-economic differences in policy impact}

The results in Table 3 indicate that on average the policy did not increase demand for eye examinations in Scotland. The results also show that there are important socio-economic differences in the demand for eye examinations. Therefore, we test if the policy had a heterogeneous impact across the different socio-economic groups in the Scottish population. In particular, from a progressive social policy perspective it is important to test if the policy increased demand in those socio-economic groups with relatively lower incidences of eye examinations.

Our theoretical model predicts that reducing the examination cost should increase demand more as individuals' income increases. This occurs because both the cost of the examination $(c)$ and the cost of the treatment $(s)$ are included in an individual's decision making. If we only consider the cost of the examination $(c)$, then a reduction in $c$ should increase demand more at lower income levels, because $c$ is a greater proportion of their overall income $(Y)$. However, the inter-temporal nature of individuals' decisions means that outcomes and costs in period 2 are factored into individuals' choices in period 1. Therefore for low values of $Y$ the benefits of the treatment may not out-weigh the associated expenses and consumption loss, hence there may be some individuals who will not have the treatment.

We therefore hypothesise that a reduction in the cost of the examination $(c)$ should trigger a stronger response from individuals who are higher in the socio-economic ladder, since the potential cost of treatment in period 2 may deter individuals with lower incomes from undertaking the examination in period 1 :

- Hypothesis 4: A reduction in the cost of the examination will trigger a stronger response from the higher socio-economic groups.

This is in line with the argument made by Okele et al., (2013); "if treatment exists but access is limited or constrained e.g. because it is very expensive, the incentive to get tested is diminished" (Okeke et al., 2013, p.208).

In order to test if there are differences in the effect of the policy across socioeconomic groups we use a difference-in-difference-in-difference model (DDD) that considers three dimensions, time $(A)$, region $(F)$ and income $(I)$. The advantage of the DDD model is that it allows for heterogeneous treatment effects across different income groups. The DDD model includes a full set of dummies, as well as all pairwise interactions:

$$
y_{i}=\beta_{0}+\beta_{1} F_{i}+\beta_{2} A_{i}+\beta_{3} I_{i}+\beta_{4} F_{i} \cdot A_{i}+\beta_{5} F_{i} \cdot I_{i}+\beta_{6} A_{i} \cdot I_{i}+\beta_{7} F_{i} \cdot A_{i} \cdot I_{i}+\varepsilon_{i}
$$

The coefficient of interest is that of the triple interaction term $\left(\beta_{7}\right)$. We consider two income groups, individuals whose equivalised household income is in the top and bottom $25 \%$ of the income distribution. Figure 3 plots the average uptake of eye examinations, separately for these two income groups for England and Scotland. The common trend assumption appears to be supported in both cases, although it is more evident for those located at the top of the income distribution.

Equation (10) is estimated based on both a parsimonious and a full specification, similar to Section 4.1, and the estimated coefficients of the triple interaction terms are presented in Table 4. 
The estimates reveal a heterogeneous policy effect. Individuals from the wealthier households (top $25 \%$ of equivalised household income distribution) increased their demand for eye examinations - the uptake after the policy increased by $4-5 \%$. Individuals in the bottom $25 \%$ were unaffected by the free eye examination policy. This provides supportive evidence for Hypothesis 4. As a result of the heterogeneous policy impact, the gap in eye-care services demand between low and high-income individuals further increased, and socio-economic differences in eye examinations have increased. To test the robustness of this result, we split the sample into three income groups (top 25\%, middle 50\%, and bottom $25 \%$ of the income distribution) and estimated the DD model separately for each group. The estimated coefficient for the interaction term is only positive and statistically significant for the top income group, which is consistent with the results from the DDD model. These results are available from the authors on request.

\subsection{Placebo estimates and sensitivity analysis}

The common trend assumption is a key identifying assumption in the DD estimates. We use three falsification tests using placebo experiments to test the robustness of our findings. The placebo estimates enhance the credibility of our identification strategy by contrasting the estimated treatment effects to those based on alternative "placebo" treatments.

The first falsification test is based on a fake treatment. Specifically, we simulate a fake policy, introduced in September 2004, and consider only the period of time before the actual eye care policy was introduced in Scotland. We perform the same DD and DDD analysis, using the full specification model and present the estimated interaction coefficients in Table 5. The full specification regression estimates can be made available upon request from the authors. Under the common trend assumption, the interaction term is not expected to be statistically significantly different from zero. The results of the first falsification test show no effect at all.

The second falsification test is based on a fake treatment group that consists of the inner and outer region of London, with the control group being the rest of England. Neither of these groups were affected by the policy. The estimated interaction coefficients, presented in Table 6 and are not statistically significant.

The third falsification test uses three irrelevant health examinations that we, a priori, expect to be unrelated to eye examinations. We use (i) blood test, (ii) cholesterol test, and (iii) chest health check-up or x-ray as alternative outcomes. We do not consider dental check-ups as an alternative examination because a free dental check up was introduced in Scotland at the same time (Ikenwilo, 2013). The eye care policy appears to have no impact on any of the alternative health check-ups considered (Table 7). Together the results of these three falsification tests lend support to the previously estimated effects.

In addition to the falsification tests, we also perform two types of sensitivity analysis. First we exclude from the sample all the individuals who might be exempt from eye examination payment, thus considering only a sample of people who face the full charge (in England for the entire period, and in Scotland during the control period) or face no charge (in Scotland in the treatment period). The DD and DDD regressions are re-estimated based on the full specification model and the estimates are presented in Table 8. The estimated treatment effects remain the same, 
suggesting that only individuals from the wealthier households responded positively to the policy by increasing their eye examination uptake by $4 \%$.

A potential issue of concern may be that individuals might have anticipated the policy, and thus delayed having their eyes tested until the payment of examination fees was removed. Anecdotal evidence suggests the opposite. To deter this anticipatory reaction that would adversely affect business of the high street optician practises, there was no wide publicity of the policy prior to its introduction. As a further sensitivity test we exclude from the analysis all the individuals who were interviewed during the first three months of 2006 and re-estimate the DD and DDD regressions using the full specification model. The estimates, presented in the second half of Table 8, remain unchanged and do not suggest any anticipatory adjustment from the patients' side.

\section{Discussion and Conclusion}

We test the impact of subsidised health examinations on health care demand. We use a theoretical model of inter-temporal substitution to derive four testable hypotheses. We test these using data on eye examinations in the UK, and exploit a policy change in Scotland in 2006 that creates exogenous variation in eye examination cost between Scotland and England.

We find that the eye examination policy in Scotland did not, on average, increase demand for eye examinations. However we do find differences across socio-economic groups in the demand for eye care services. We find that only individuals from the wealthier households increased their eye examination uptake. Given that these individuals were more likely to have their eyes examined before the policy introduction we find that the universal free eye examination policy has increased inequality in preventive care use.

One could thus argue that the lack of significant impact on the number of eye examinations combined with the undesirable effect of increasing inequalities is enough to suggest that the free eye examination policy should be reconsidered. It was recently estimated that General Ophthalmic Services costs increased by around $f^{21}$ million following the introduction of free eye examinations in 2006 and, even accounting for historic trends, costs in 2011 were around $£ 32$ million higher than expected (4-Consulting, 2012). This poses the question of whether removing the policy would improve fiscal sustainability and contribute to narrowing inequalities.

It is therefore important to consider if the policy represents value for money. This is particularly difficult to assess because any health improvements derived from this policy will not be fully felt for many years. The introduction of free NHS eye examinations effectively expanded the testing of sight to the provision of a more extensive eye health examination which enabled optometrists to detect early signs of sight problems. As of 2010, there were almost 2 million people living with sight loss in the UK and, with an increasingly aging population, that number is predicted to increase to almost 4 million by 2050 (RNIB Scotland, 2010). Loss of sight is expensive, with an estimated $£^{2} 2$ billion costs associated with it in the UK (RNIB Scotland, 2010). Although one can expect significant future cost savings, through the early treatment of disease and people avoiding loss of vision, these savings will only emerge over the longer term as 
a much larger section of Scottish society will potentially have their eyes examined on a regular basis.

Nevertheless, the question of inequality remains. While we find that the policy did not increase demand for eye-care, on average, it did increase demand among individuals from wealthier households and did not increase demand from lower income households. This provides an example of an intervention aimed at the whole of the population that inadvertently increases inequality because different segments of the population face different barriers to access. Our model predicts that individuals decide to be tested based on the cost of the test and the cost of treatment. Therefore lower income individuals are not tested even when the cost of the test decreases if the cost of treatment (spectacles or other related products) is too high. In this case, policymakers could explore treatment subsidies as well as screening price subsidies. Our results may also reflect an example of the "inverse care law" in which populations with the most need receive less care (Tudor Hart, 1971). Shickle et al., (2015) report this is the case for eye-care in England. Primary eye care is supplied by the private market and access is dependent on the location of opticians on the high-street. Private optometrists' business earnings depend on revenue from screening tests and optical appliances, which gives businesses less incentive to locate in areas in which revenue from the sales of optical appliances will be lower (Shickle et al., 2015).

Knight and Lindfield (2015) systematically review the relationship between socio-economic status (SES) and access to eye care services (both high-street, primary and secondary care) in the UK and find mixed evidence. Four studies consider utilisation of high-street eye care services, one study that uses BHPS data up to 2003 finds no association (Sabates et al., 2008), however three studies find use is positively associated with SES (Majeed et al., 2008; Rahi et al., 2008; Van der Pols et al., 1999). In general, more advantaged groups have better access to preventive care because they have more resources (not only income, but also time and life skills) to access this care (MacIntyre, 2007). Other universal health promotion policies in Scotland have also been found to inadvertently increase health inequalities (Schou and Wight, 1994; De Walle et al., 1999).

Our results are likely to be generalizable to other primary care screening or preventive care settings where the outcome screened for is not life limiting, and the cost of treatment is not fully covered by the health care service. Indeed, in terms of socio-economic status differences, our results are comparable to other studies of preventive care utilisation. We caution about generalising our results to screening tests for conditions that have a large impact on mortality or morbidity (such as cancer) and those for which treatments are provided by the health care service.

One strength of this study is that we use a large national household panel to investigate how user fees affect demand for a preventive care service. In doing so, our evidence comes from a broad sample of the population rather than being limited to health care users. Furthermore, we are able to assess the impact of the policy on outcomes (screening uptake) in general, and we are also able to assess how the policy impacts on different socioeconomic groups. A second strength of this study is our use of a robust technique (difference in differences) and a set of falsification tests (a fake policy, fake treatment group, and unaffected preventive care services) to demonstrate the robustness of our findings. 
One limitation of this study is that our estimates refer to the period of time immediately after the policy was introduced. We are unable to capture an increase in screening if the policy affected this with a delay. For example, if people only became aware of the policy slowly after it was implemented. Anecdotal evidence, such as research by a chain of ophthalmic opticians, found that by July $2007,66 \%$ of the population were still unaware that eye examinations had been made universally free (Frost's Scottish Anatomy, 2007). This could be particularly true since the free eye care policy was announced just a few days after the smoking ban in Scotland, which dominated the media attention and the public debate.

A second limitation is that we are unable to provide a thorough Cost-Benefit Analysis of the policy. The test cost has been shifted from individuals to government. We do not know precisely what each person was paying before the policy. However, we do not consider the long-term eye health outcomes for those who are tested. Future research should consider if the Scottish population have better eye health outcomes overtime and provide a full evaluation of the policy taking into account the impact on secondary care, for example in ophthalmology clinics, due to changes in the number of referrals or workload and case-mix. 


\section{References}

4-Consulting. (2012). The Economic Impact of Free Eye Examinations in Scotland. Commissioned by the Association of Optometrists.

Allison, P. (1999) Comparing logit and probit coefficients across groups. Sociological Methods and Research, 28, 186-208.

Arrow, K.. (1974). Optimal insurance and generalized deductibles. Scandinavian Actuarial Journal, 1-42. Reprinted in Collected Papers of Kenneth J. Arrow, Volume 3: Individual Choice Under Certainty and Uncertainty, Cambridge, MA: Harvard University Press, 1984, 212-60.

Basinga, P., Gertler, P.J., Binagwaho, A., Soucat, A.L.B., Sturday, J., \& Vermeersch, C.M.J. (2011). Effect on maternal and child health services in Rwanda of payment to primary health-care providers for performance: an impact evaluation. Lancet, 377, 1421-1428.

Bertakis, K.D., Azari, R., Helms, L.J., Callahan, E.J. and Robbins, J.A. (2000). Gender differences in the utilization of health care services. Journal of Family Practice, 49, 147-152.

Borghi, J., Ensor, T., Samanathan, A., Lissner, C. and Mills, A. (2006). Mobilising financial resources for maternal health. The Lancet, 368, 1457-1465.

Carrieri, V. and Bilger, M. (2013). Preventive care: underused even when free. Is there something else at work? Applied Economics, 45, 239-253.

Cauley, S. D. (1987). The time price of medical care. The Review of Economics and Statistics, 69, 59-66.

Chatterji, P., and Meara, E. (2010). Consequences of eliminating federal disability benefits for substance abusers. Journal of Health Economics, 29, 226-240.

Christensen, B. (1995). Payment and attendance at general practice preventive health examinations, Family Medicine, 27, 531-534.

Cohen, J., and Dupas, P. (2010). Free distribution or cost-sharing? Evidence from a randomized malaria prevention experiment. The Quarterly Journal of Economics, 125, 1-45.

de Walle H, van der Pal K, de Jong-van den Berg L, Jeeninga W, Schouten J, de Rover C, et al., (1999). Effect of mass media campaign to reduce socioeconomic differences in women's awareness and behaviour concerning use of folic acid: cross sectional study. British Medical Journal; 319, 291-292.

Dickens W. T. (1990). Error components in grouped data: Is it ever worth weighting? Review of Economics and Statistics, 72, 328-333.

Dickey, H., Ikenwilo, D., Norwood, P., Watson, V. and Zangelidis, A. (2012). Utilisation of eye-care services: The effect of Scotland's free eye examination policy. Health Policy, 108, 286-293.

Friedman, C., Ahmed, F., Franks, A., Weatherup, T., Manning, M., Vance, A. and Thompson, B. (2002). Association between health insurance coverage of office visit and cancer screening among women. Medical Care, 40, 1060-1067.

Frost's Scottish Anatomy. Research reveals Scots are missing out on vital eye care.http://www.martinfrost.ws/htmlfiles/scotnews07/070717_eyecare.html (accessed on 13.01.2014)

Grossman, M. (1972). On the concept of health capital and the demand for health. Journal of Political Economy, 80, 223-255. 
Ikenwilo, D. (2013). A difference in differences analysis of the effect of free dental checkups in Scotland. Social Science and Medicine, 83, 10-18.

James, C., Hanson, K., McPakem B., Balabanova, D., Gwatkin, D., Hopwood, I., Kirunga, R., Meessen, B., Morris., S., Preker, A., Souteyrand, Y., Tibouti, A., Villeneuve, P. and Xu, K. (2006). To retain or remove user fees? Reflections on the current debate in low- and middle-income countries. Applied Heath Economics and Health Policy, 5, 137-153.

Janssen, R. (1992). Time prices and the demand for GP services. Social Science and Medicine, 34, 725-33.

Kenkel, DS, (1994). The demand for preventive care. Applied Economics, 26, 313-325.

Kiefe, C., McKay, S., Halevy, A. and Brody, B. (1994). Is cost a barrier to screening mammography for low-income women receiving medicare benefits? A randomized trial. Archives of Internal Medicine, 154, 1217-1224.

Kiil, A. \& Houlberg, K. (2014). How does copayment for health care services affect demand, health and redistribution? A systematic review of the empirical evidence from 1990 to 2011. European Journal of Health Economics, 15, 813-828.

Knight, A., Lindfield, R. (2015). The relationship between socio-economic status and access to eye health services in the UK: A systematic review. Public Health, 129, 94-102.

Krůtilová, V. (2010). Impact of user Fees in health care system on health care consumption. Review of Economic Perspectives, 10, 113-132.

Lambert, P. (2006). The British Household Panel Survey: Introduction to a longitudinal data resource. Longitudinal Data Analysis for Social Science Researchers Working Paper 2.

Layte, R., Nolan, A., McGee, H., \& O'Hanlon, A. (2009). Do consultation charges deter general practitioner use among older people? A natural experiment. Social Science and Medicine, 68, 1432-1438.

Long, J. Scott and Jeremy Freese. (2006). Regression models for categorical dependent variables using Stata, Second Edition. College Station, Texas: Stata Press.

Lundberg, L., Johannesson, M., Isacson, D. G., and Borgquist, L. (1998). Effects of User Charges on the Use of Prescription Medicines in Different Socio-economic Groups. Health Policy, 44, 123-134.

Macintyre, S. (2007). Inequalities in health in Scotland: What are they and what can we do about them? MRC Social and Public Health Sciences Unit, Occasional Paper No 17.

Majeed, M., Williams, C., Northstone, K., Ben-Shlomo, Y. (2008). Are there inequities in the utilisation of childhood eye-care services in relation to socio-economic status and choroidal melanoma in Scotland. British Journal of Opthalmology, 92, 965-969

Nexøe, J., Kragstrup, J., and Rønne, T. (1997). Impact of postal invitations and user fee on influenza vaccination rates among the elderly: A randomized controlled trial in general practice. Scandinavian journal of primary health care, 15, 109-112.

Okeke, E., Adepiti, C., and Ajenifuja, K., (2013). What is the price of prevention? New evidence from a field experiment. Journal of Health Economics, 32, 207-218.

Rahi, JS., Peckham, CS., Cumberland, PM., (2008). Visual impairment due to undiagnosed refractive error in working age adults in Britian, British Journal of Opthalmology, 92, 1190-4 
Redondo-Sendino, A., Guallar-Castillón, P., Benegas, J.R. and Rodriguez-Artalejo, F. (2006). Gender differences in the utilization of health-care services among the older adult population of Spain. BMC Public Health, 6, 155.

RNIB Scotland. 2010. The cost of sight loss Scotland: 2010-2020. Edinburgh.

Sabates, R., Feinstein, L. (2008). Do income effects mask social and behavioural factors when looking at universal health care provision? International Journal of Public Health, 53, 23-30.

Schokkaert, E. and Van de Voorde, C. (2011). User charges. In The Oxford Handbook of Health Economics. Glied, S. and Smith, P. (eds.).pp. 329-353. Oxford and New York: Oxford University Press.

Schou L, and Wight C. (1994). Mothers' educational level, dental health behaviours and response to a dental health campaign in relation to their 5 year old children's caries experience. Health Bulletin, 52, 232-239.

Scottish Executive. Review of Community Eyecare Services in Scotland: Interim Report. 2005, Edinburgh: Scottish Executive.

Sepehri, A. and Chernomas, R. (2001). Are user charges efficiency- and equity-enhancing? A critical review of economic literature with particular reference to experience from developing countries. Journal of International Development, 13, 183-209.

Shickle, D., Todkill, D., Chisholm, C. Rughani, S., Griffen, M., Cassels-Brown, A., May, H., Slade, SV., Davey, CJ. (2015). Addressing inequalities in eye health with subsidies and increased fees for General Ophthalmic Services in socio-economically deprived communities: a sensitivity analysis. Public Health, 129, 131-137

Solanki, G., Schauffler, H. and Miller, L. (2000). The direct and indirect effects of cost-sharing on the use of preventive services. Health Services Research, 34, 1331-1350.

Solon, G., Haider, S. J., \& Wooldridge, J. M. (2015). What are we weighting for?. Journal of Human Resources, 50, 301-316.

Souteyrand, Y., Collard, V., Moatti, J., Grubb, I. and Guerma, T. (2008). Free care at the point of delivery: A key component for reaching universal access to HIV/AIDS treatment in developing countries. AIDS, 22, S161-S168.

Stabile, M. and Thomson, S. (2014). The changing role of government in financing health care: An international perspective. Journal of Economic Literature, 52, 480-518.

Stoner, T., Dowd, B., Carr, P. Maldonado, G., Church, T. and Mandel, J. (1998). Do vouchers improve breast cancer screening rates? Results from a randomized trial. Health Services Research, 33, 11-28.

Taylor A. (1994). Appendix: sample characteristics, attrition and weighting. In Changing households, ed. N Buck, J Gershuny, D Rose, J Scott. Colchester: ESRC Research Centre on Micro-Social Change, University of Essex.

Taylor, M.F., Brice, J., Buck, N., and Prentice-Lane, E. (2010). British Household Panel Survey User Manual Volume A: Introduction, Technical Report and Appendices. Colchester: University of Essex.

Thomson, S., Mossialos, E. and Jemiai, N. (2003). Cost sharing for health services in the European Union. London: London School of Economics, LSE Health and Social Care.

Torgerson, D. J., Donaldson, C., \& Reid, D. M. (1994). Private versus social opportunity cost of time: valuing time in the demand for health care. Health Economics, 3, 149-155. 
Tudor Hart J. (1971). The inverse care law. Lancet, 297, 405-412.

Vaidya, V., Partha, G. and Karmakar, M. (2012). Gender differences in utilization of preventive care services in the United States. Journal of Women's Health, 21, 140-145.

Van der Pols, JC, Thompson, JR., Bates, CJ., Prentice, A., Finch, S., (1999). Is the frequency of having an eye test associated with socioeconomic factors? A national cross-sectional study in the British Elderly. Journal of Epidemiology and Public Health, 53, 737-8.

Viscusi W. and Evans, W., (1990). Utility functions that depend on health status: Estimates and economic implications. The American Economic Review, 80, 353-374.

Xu K, Evans DB, Kawabata K, Zeramdini R, Klavus J, Murray CJ, (2003). Household catastrophic health expenditure: a multicountry analysis. Lancet, 362, 111-117.

Zeckhauser R., (1970). Medical insurance: A case study of the tradeoff between risk Spreading and appropriate incentives. Journal of Economic Theory, 2, 10-26.

Zeckhauser R., (1973). Coverage for Catastrophic Illness. Public Policy, 21, 149-172. 


\section{Tables}

\section{Table 1: Definitions of variables}

\begin{tabular}{ll}
\hline Variable name & Definition \\
\hline Had an eye test & 1 if person had an eye test in the past 12 months; 0 otherwise \\
& 1 if person fulfils the criteria for a free eye test (when fees exist); 0 \\
Exempt group & 1 if person is a woman; 0 otherwise \\
Female & 1 if person is aged between 16 to $29 ; 0$ otherwise \\
Age: $16-29$ (reference) & 1 if person is aged between 30 to 39; 0 otherwise \\
Age: 30-39 & 1 if person is aged between 40 to $49 ; 0$ otherwise \\
Age: 40-49 & 1 if person is aged between 50 to $59 ; 0$ otherwise \\
Age: $50-59$ & Number of children present in the household \\
Number of children & 1 if married, or cohabitating; 0 otherwise \\
Living together & 1 if separated; 0 otherwise \\
Separated & 1 if widowed; 0 otherwise \\
Widowed & 1 if single; 0 otherwise \\
Single (reference) & 1 if excellent or good health state in the past 12 months; 0 otherwise \\
Good health & 1 if person had not visited the GP in the past 12 month; 0 otherwise \\
No visits to GP & 1 if person's equivalised household income is in the top 25\% of \\
HH income: top 25\% & income distribution; 0 otherwise \\
No qualification & 1 if person has no formal qualifications; 0 otherwise \\
Secondary educ. (reference) & 1 if person has up to secondary education; 0 otherwise \\
First or higher degree & 1 if person has University degree or above; 0 otherwise \\
Scotland & 1 if person lives in Scotland; 0 otherwise \\
\hline
\end{tabular}


Table 2: Descriptive statistics

\begin{tabular}{|c|c|c|c|c|c|c|c|}
\hline \multirow[b]{2}{*}{ Had an eye test } & \multicolumn{6}{|c|}{ No eye } & \multirow[t]{2}{*}{ t-test } \\
\hline & 0.362 & $(0.481)$ & & & & & \\
\hline Exempt group & 0.183 & $(0.387)$ & 0.172 & $(0.377)$ & 0.203 & $(0.402)$ & $* * *$ \\
\hline Female & 0.534 & $(0.499)$ & 0.503 & $(0.500)$ & 0.589 & $(0.492)$ & $* * *$ \\
\hline Age: 16-29 (reference) & 0.304 & $(0.460)$ & 0.328 & $(0.470)$ & 0.261 & $(0.439)$ & $* * *$ \\
\hline Age: 30-39 & 0.250 & $(0.433)$ & 0.274 & $(0.446)$ & 0.206 & $(0.405)$ & $* * *$ \\
\hline Age: 40-49 & 0.243 & $(0.429)$ & 0.228 & $(0.420)$ & 0.270 & $(0.444)$ & $* * *$ \\
\hline Age: $50-59$ & 0.203 & $(0.402)$ & 0.169 & $(0.375)$ & 0.263 & $(0.440)$ & $* * *$ \\
\hline Number of children & 0.737 & $(1.011)$ & 0.775 & $(1.031)$ & 0.700 & $(0.972)$ & $* * *$ \\
\hline Living together & 0.498 & $(0.500)$ & 0.478 & $(0.500)$ & 0.534 & $(0.499)$ & $* * *$ \\
\hline Separated & 0.114 & $(0.318)$ & 0.106 & $(0.308)$ & 0.128 & $(0.334)$ & $* * *$ \\
\hline Widowed & 0.010 & $(0.102)$ & 0.009 & $(0.097)$ & 0.012 & $(0.109)$ & $* * *$ \\
\hline Single (reference) & 0.377 & $(0.485)$ & 0.407 & $(0.491)$ & 0.325 & $(0.468)$ & $* * *$ \\
\hline Good health & 0.739 & $(0.439)$ & 0.754 & $(0.431)$ & 0.713 & $(0.452)$ & $* * *$ \\
\hline No visits to GP & 0.277 & $(0.448)$ & 0.306 & $(0.461)$ & 0.228 & $(0.420)$ & $* * *$ \\
\hline $\mathrm{HH}$ income: top $25 \%$ & 0.337 & $(0.473)$ & 0.320 & $(0.466)$ & 0.368 & $(0.482)$ & $* * *$ \\
\hline $\mathrm{HH}$ income: mid $25-75 \%$ & 0.480 & $(0.500)$ & 0.489 & $(0.500)$ & 0.464 & $(0.499)$ & $* * *$ \\
\hline $\mathrm{HH}$ income: low 25\% & 0.183 & $(0.387)$ & 0.192 & $(0.394)$ & 0.168 & $(0.374)$ & $* * *$ \\
\hline No qualification & 0.157 & $(0.364)$ & 0.158 & $(0.365)$ & 0.155 & $(0.362)$ & \\
\hline Secondary educ. (reference) & 0.667 & $(0.471)$ & 0.677 & $(0.468)$ & 0.649 & $(0.477)$ & $* * *$ \\
\hline First or higher degree & 0.176 & $(0.381)$ & 0.164 & $(0.371)$ & 0.196 & $(0.397)$ & $* * *$ \\
\hline Scotland & 0.264 & $(0.441)$ & 0.268 & $(0.443)$ & 0.257 & $(0.437)$ & $* * *$ \\
\hline Observations & 52613 & & 33542 & & 19071 & & \\
\hline
\end{tabular}


Table 3: Free Eye policy impact on eye examinations

\begin{tabular}{|c|c|c|}
\hline & $(1)$ & $(2)$ \\
\hline Scotland & $\begin{array}{c}-0.014^{*} \\
-1.84)\end{array}$ & $\begin{array}{c}-0.016^{* * *} \\
(-3.00)\end{array}$ \\
\hline Policy & $\begin{array}{c}0.011^{* *} \\
(2.10)\end{array}$ & $\begin{array}{c}2.17 \mathrm{e}-4 \\
(0.03)\end{array}$ \\
\hline Scotland $\times$ Policy & $\begin{array}{l}0.008 \\
(0.79)\end{array}$ & $\begin{array}{l}0.009 \\
(0.87)\end{array}$ \\
\hline Exempt group & & $\begin{array}{c}0.031^{* * *} \\
(4.82)\end{array}$ \\
\hline Eyecheck $_{\mathrm{t}-1}$ & & $\begin{array}{c}0.226^{* * *} \\
(42.95)\end{array}$ \\
\hline Eyecheck $_{\mathrm{t}-2}$ & & $\begin{array}{c}0.255^{* * *} \\
(45.91)\end{array}$ \\
\hline Female & & $\begin{array}{c}0.036^{* * *} \\
(8.23)\end{array}$ \\
\hline Age: $30-39$ & & $\begin{array}{l}-0.006 \\
(-0.97)\end{array}$ \\
\hline Age:40-49 & & $\begin{array}{c}0.061^{* * *} \\
(8.51)\end{array}$ \\
\hline Age:50-59 & & $\begin{array}{c}0.084^{* * *} \\
(10.54)\end{array}$ \\
\hline Number of children & & $\begin{array}{l}-0.004 \\
(-1.50)\end{array}$ \\
\hline Married & & $\begin{array}{c}0.015^{* *} \\
(2.43)\end{array}$ \\
\hline Separated & & $\begin{array}{l}0.015^{*} \\
(1.86)\end{array}$ \\
\hline Widowed & & $\begin{array}{l}-0.010 \\
(-0.47)\end{array}$ \\
\hline Good health & & $\begin{array}{c}-0.013^{* *} \\
(-2.47)\end{array}$ \\
\hline No visits to GP & & $\begin{array}{c}-0.036^{* * *} \\
(-7.49)\end{array}$ \\
\hline No qualification & & $\begin{array}{c}-0.027^{* * *} \\
(-4.41)\end{array}$ \\
\hline First or higher degree & & $\begin{array}{c}0.024^{* * *} \\
(4.05)\end{array}$ \\
\hline HH income: top $25 \%$ & & $\begin{array}{c}0.014^{* * *} \\
(2.94)\end{array}$ \\
\hline HH income: bottom $25 \%$ & & $\begin{array}{c}-0.017^{* * *} \\
(-2.78)\end{array}$ \\
\hline Year trends & No & Yes \\
\hline Constant & $\begin{array}{c}0.363^{* * *} \\
(88.79)\end{array}$ & $\begin{array}{c}0.152^{* * *} \\
(17.86)\end{array}$ \\
\hline Observations & 52613 & 44388 \\
\hline R-square & 0.0003 & 0.1873 \\
\hline
\end{tabular}


Table 4: Heterogeneous effect of policy (triple difference)

\begin{tabular}{lcc}
\hline & $(1)$ & $(2)$ \\
\hline Scotland $\times$ Policy $\times$ HH income: top $25 \%$ & $0.054^{* *}$ & $0.042^{*}$ \\
& $(2.13)$ & $(1.82)$ \\
Scotland $\times$ Policy $\times$ HH income: bottom $25 \%$ & $-6.27 \mathrm{e}-5$ & $7.61 \mathrm{e}-4$ \\
& $(-2.12 \mathrm{e}-3)$ & $(0.03)$ \\
Year trends & No & Yes \\
Other covariates & No & Yes \\
\hline Observations & 52613 & 44388 \\
R-square & 0.0031 & 0.1875
\end{tabular}

Notes: OLS estimates. Coefficients reported with $t$-statistic in parentheses. The level of statistical significance is denoted by: ${ }^{*} p<0.10,{ }^{* *} p<0.05,{ }^{* * *} p<0.01$. Other explanatory variables included are controls for eye test payment, exemption, gender, age, number of children, marital status, education and equivalised household income (position in distribution).

Table 5: Placebo estimates (fake policy in September 2004)

Scotland $\times$ Placebo policy

$-0.0124$

$(-0.93)$

Scotland $\times$ Placebo policy $\times$ HH income: top $25 \%$

Scotland $\times$ Placebo policy $\times \mathrm{HH}$ income: bottom $25 \%$

Notes: OLS estimates. Coefficients reported with $t$-statistic in parentheses. The level of statistical significance is denoted by: ${ }^{*} p<0.10,{ }^{* *} p<0.05,{ }^{* * *} p<0.01$. Other explanatory variables included are controls for eye test payment, exemption, gender, age, number of children, marital status, education, equivalised household income (position in distribution) and year trends. The sample is restricted in the period prior to the free eye care policy introduced in Scotland.

\section{Table 6: Placebo estimates (treatment group: London, inner and outer)}

Fake treatment $\times$ Policy -0.010

Fake treatment $\times$ Policy $\times$ HH income: top $25 \%$

Fake treatment $\times$ Policy $\times \mathrm{HH}$ income: bottom $25 \%$

Observations
Notes: OLS estimates. Coefficients reported with $t$-statistic in parentheses. The level of statistical significance is
denoted by: ${ }^{*} p<0.10,{ }^{* *} p<0.05,{ }^{* * *} p<0.01$. Other explanatory variables included are controls for eye test
payment, exemption, gender, age, number of children, marital status, education and equivalised household income
(position in distribution) and year trends. The sample is restricted to individuals residing in England only.


Table 7: Placebo estimates (unrelated outcomes)

Outcome: Blood test

Scotland $\times$ Policy

0.011

Scotland $\times$ Policy $\times$ HH income: top $25 \%$

Scotland $\times$ Policy $\times$ HH income: bottom $25 \%$

$(0.87)$

Outcome: Cholesterol test

Scotland $\times$ Policy

$-0.007$

$(-0.85)$

Scotland $\times$ Policy $\times$ HH income: top $25 \%$

0.014

$(0.77)$

Scotland $\times$ Policy $\times$ HH income: bottom $25 \%$

0.014

(0.63)

Outcome: Chest or other $x$-ray health check-up

$\begin{array}{ll}\text { Scotland } \times \text { Policy } & 0.005\end{array}$

$(0.60)$

Scotland $\times$ Policy $\times$ HH income: top $25 \%$

0.009

Scotland $\times$ Policy $\times$ HH income: bottom $25 \%$

$-0.014$

$(-0.63)$

Observations

44388

44388

Notes: OLS estimates. Coefficients reported with $t$-statistic in parentheses. The level of statistical significance is denoted by: ${ }^{*} p<0.10,{ }^{* *} p<0.05,{ }^{* * *} p<0.01$. Other explanatory variables included are controls for eye test payment, exemption, gender, age, number of children, marital status, education, equivalised household income (position in distribution) and year trends. 
Table 8: Sensitivity analysis

\begin{tabular}{|c|c|c|}
\hline & (1) & (2) \\
\hline \multicolumn{3}{|c|}{ Excluding individuals who may be exempt from eye examination payment } \\
\hline \multirow[t]{2}{*}{ Scotland $\times$ Policy } & 0.007 & \\
\hline & $(0.61)$ & \\
\hline \multirow[t]{2}{*}{ Scotland $\times$ Policy $\times$ HH income: top $25 \%$} & & $0.041^{*}$ \\
\hline & & $(1.69)$ \\
\hline \multirow[t]{2}{*}{ Scotland $\times$ Policy $\times$ HH income: bottom $25 \%$} & & -0.011 \\
\hline & & $(-0.35)$ \\
\hline Observations & 37490 & 37490 \\
\hline R-square & 0.1763 & 0.1765 \\
\hline \multicolumn{3}{|c|}{ Excluding individuals who were interviewed in 2006 (before the policy introduction) } \\
\hline \multirow[t]{2}{*}{ Scotland $\times$ Policy } & 0.008 & \\
\hline & $(0.85)$ & \\
\hline \multirow[t]{2}{*}{ Scotland $\times$ Policy $\times$ HH income: top $25 \%$} & & $0.041 *$ \\
\hline & & $(1.74)$ \\
\hline \multirow[t]{2}{*}{ Scotland $\times$ Policy $\times$ HH income: bottom $25 \%$} & & $-1.41 \mathrm{e}-4$ \\
\hline & & $(-0.01)$ \\
\hline Observations & 44262 & 44262 \\
\hline R-square & 0.1871 & 0.1872 \\
\hline
\end{tabular}

Notes: OLS estimates. Coefficients reported with $t$-statistic in parentheses. The level of statistical significance is denoted by: ${ }^{*} p<0.10,{ }^{* *} p<0.05,{ }^{* * *} p<0.01$. Other explanatory variables included are controls for eye test payment, exemption, gender, age, number of children, marital status, education, equivalised household income (position in distribution) and year trends. 


\section{Figures}

Figure 1: Decision to undertake health test and treatment in a sequential two-period framework

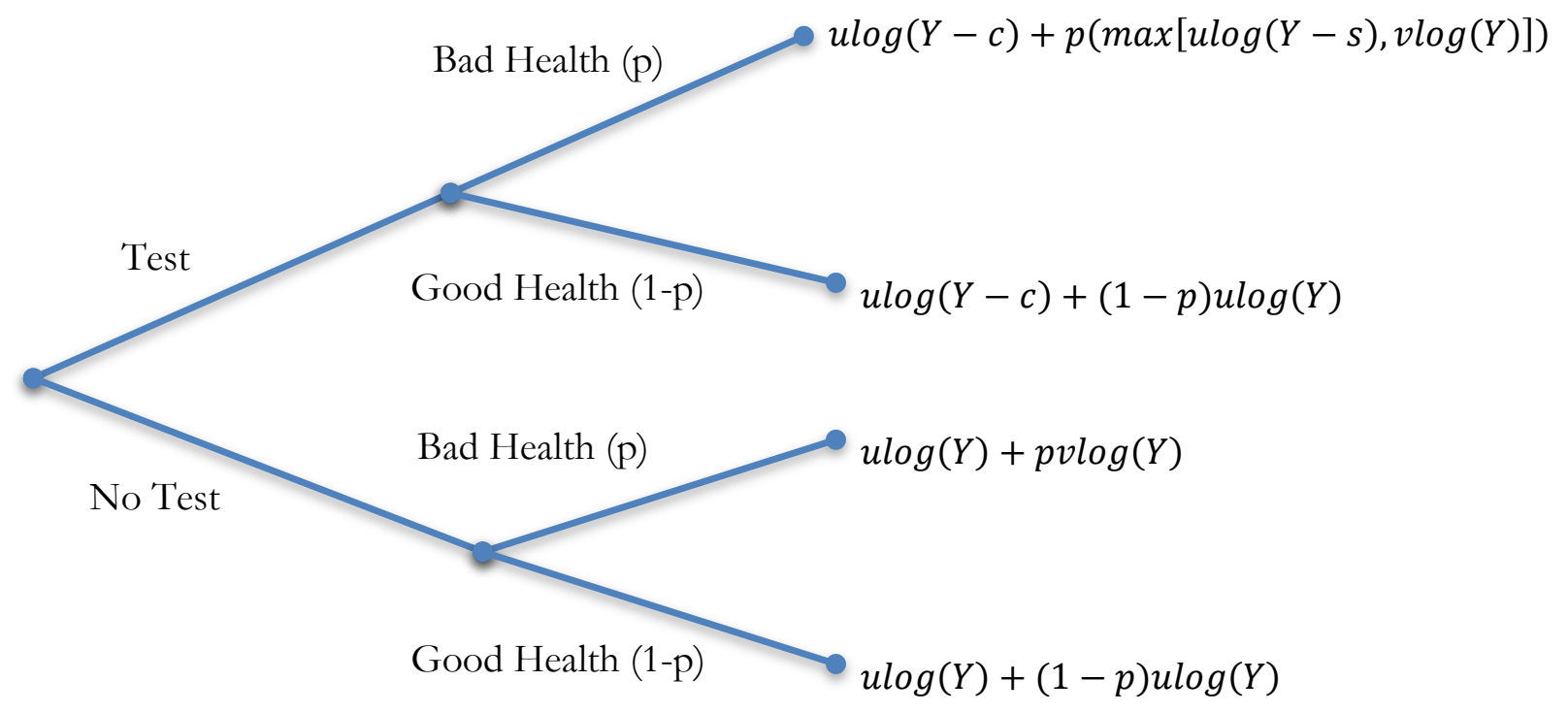


Figure 2: Eye healthcare utilisation

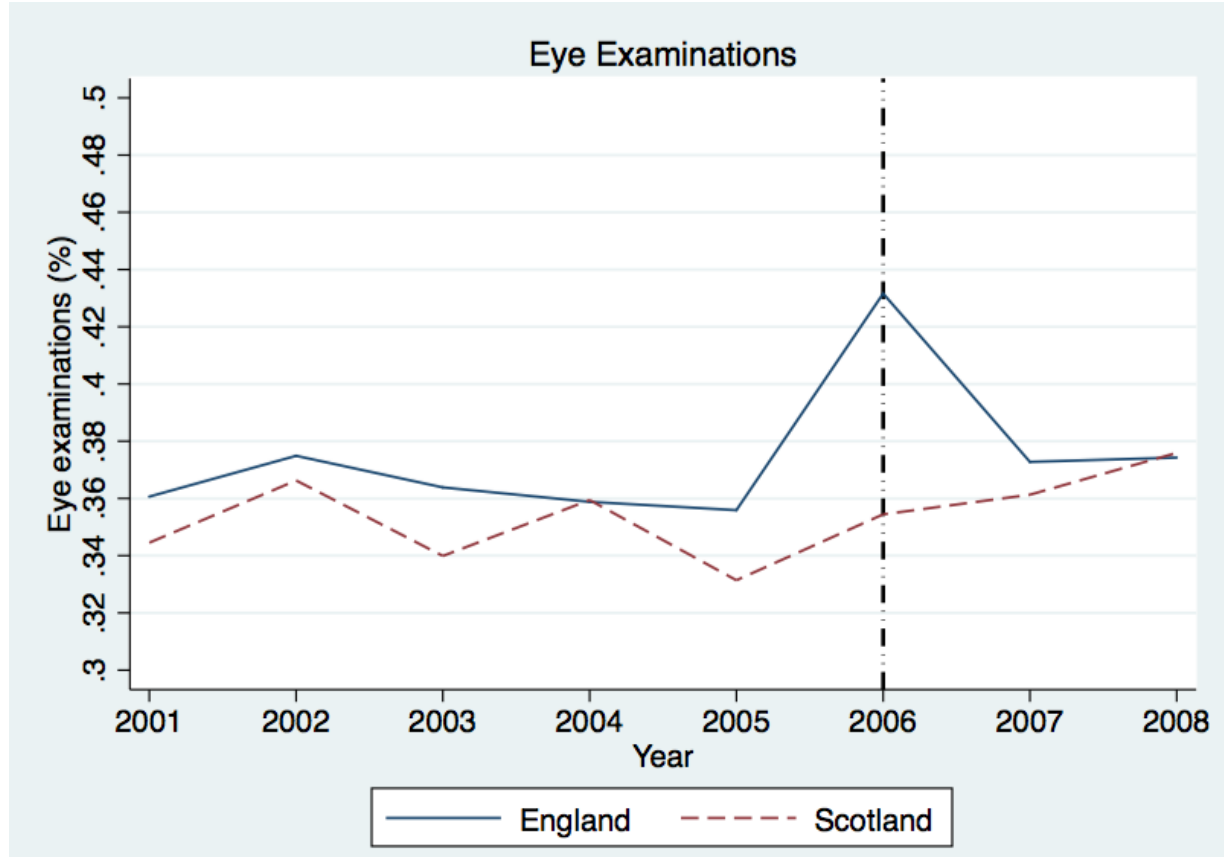

Notes: Average uptake of eye examinations based on authors' calculations using the BHPS. The year variable refers to the corresponding BHPS wave. The vertical reference line at year 2006 denotes the period since the introduction of the eye care policy in Scotland. Observations corresponding to interviews conducted between April-December 2006 are excluded since we cannot identify whether people in Scotland had an eye examination before or after the policy was introduced. The spike observed in 2006 is driven by the small sample size of that particular year, so the 2006 figure should be interpreted with caution. 


\section{Figure 3: Eye healthcare utilisation (by income groups)}

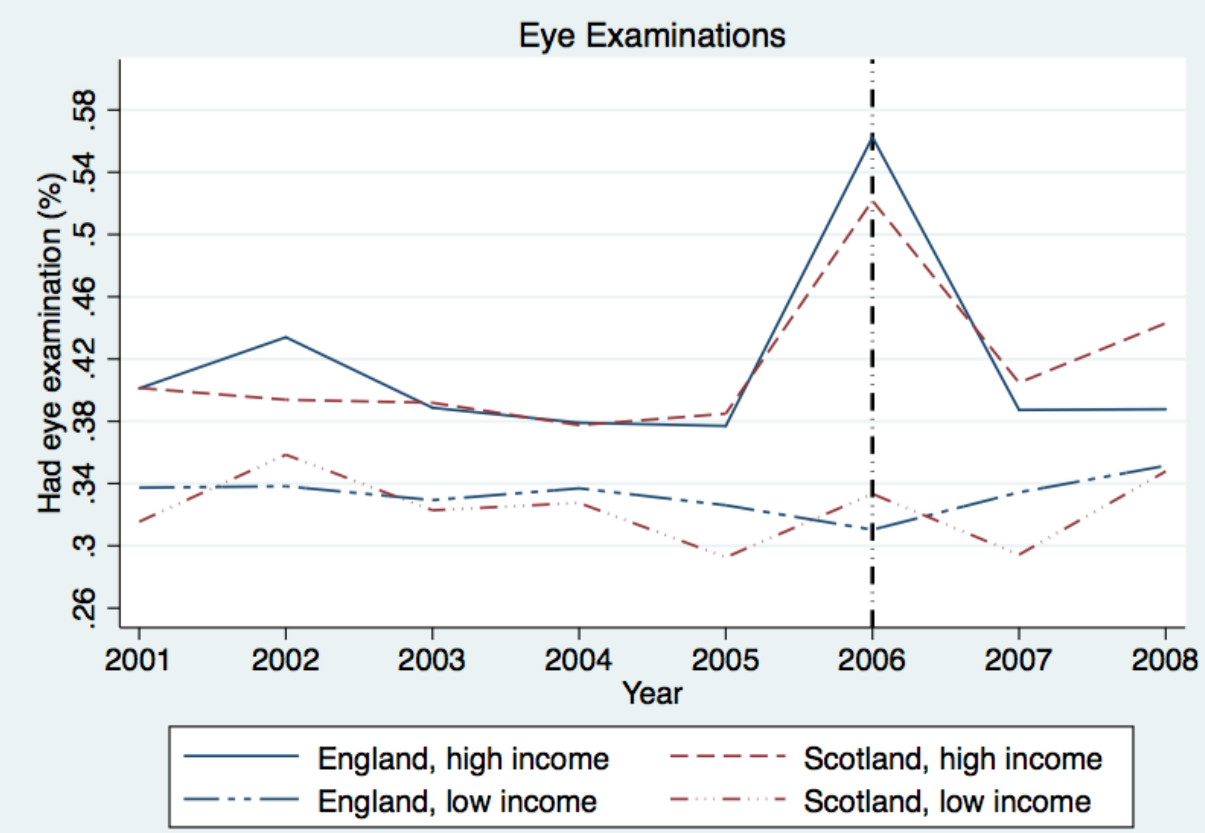

Notes: Average uptake of eye examinations based on authors' calculations using the BHPS. The year variable refers to the corresponding BHPS wave. The vertical reference line at year 2006 denotes the period since the introduction of the eye care policy in Scotland. Observations corresponding to interviews conducted between April-December 2006 are excluded since we cannot identify whether people in Scotland had an eye examination before or after the policy was introduced. The spike observed in 2006 is driven by the small sample size of that particular year, so the 2006 figure should be interpreted with caution. 


\section{Appendix}

A1: Deriving the effect of a change in the cost of examination (c) on the testing threshold level $\left(\boldsymbol{p}^{*}\right)$

From equation (6) we know,

$$
p^{*}=\frac{u[\log (Y)-\log (Y-c)]}{u \log (Y-s)-v \log (Y)}
$$

Then,

$$
\begin{gathered}
\frac{\partial p^{*}}{\partial c}=-\frac{u}{u \log (Y-s)-v \log (Y)}[\log (Y-c)]^{\prime}=-\frac{u}{u \log (Y-s)-v \log (Y)}(-1)\left(\frac{1}{Y-c}\right) \\
=\frac{u}{u \log (Y-s)-v \log (Y)}\left(\frac{1}{Y-c}\right)
\end{gathered}
$$

By assumption, we know that $u \log (Y-s)-v \log (Y)>0$ and $Y-c>0$, therefore $\frac{\partial p^{*}}{\partial c}>0$.

A2: Deriving the effect of a change in the cost of treatment (s) on the testing threshold level $\left(\boldsymbol{p}^{*}\right)$

Equation (6) can be rewritten as,

$$
p^{*}=\frac{[\log (Y)-\log (Y-c)]}{\log (Y-S)-\frac{v}{u} \log (Y)}=\frac{[\log (Y)-\log (Y-c)]}{\log (Y-S)-\log \left(Y^{\frac{v}{u}}\right)}=\frac{\log \left(\frac{Y}{Y-c}\right)}{\log \left(\frac{Y-s}{Y \bar{v}}\right)}
$$

Then,

$$
\begin{gathered}
\frac{\partial p^{*}}{\partial s}=-\frac{\log \left(\frac{Y}{Y-c}\right)}{\left[\log \left(\frac{Y-s}{Y^{\frac{v}{u}}}\right)\right]^{2}}\left[\log \left(\frac{Y-s}{Y^{\frac{v}{u}}}\right)\right]^{\prime}=-\frac{\log \left(\frac{Y}{Y-c}\right)}{\left[\log \left(\frac{Y-s}{Y^{\frac{v}{u}}}\right)\right]^{2}}(-1)\left(\frac{1}{\frac{Y-s}{Y^{\frac{v}{u}}}}\right) \\
=\frac{\log \left(\frac{Y}{Y-c}\right)}{\left[\log \left(\frac{Y-s}{Y^{\frac{v}{u}}}\right)\right]^{2}}\left(\frac{1}{\frac{Y-s}{Y^{\frac{v}{u}}}}\right)
\end{gathered}
$$

By assumption, we know that $Y-s>0$ and $Y-c>0$, therefore $\frac{\partial p^{*}}{\partial s}>0$.

A3: Deriving the effect of a change in income $(Y)$ on the testing threshold level $\left(\boldsymbol{p}^{*}\right)$ 
For ease of presentation, let us denote $z(Y)=u \log (Y-s)-v \log (Y)$, and $f(Y)=$ $u(\log (Y)-\log (Y-c))$. From equation (6) then,

$$
\frac{\partial p^{*}}{\partial Y}=\frac{z(Y) f(y)^{\prime}-f(Y) z(Y)^{\prime}}{[z(Y)]^{2}}=\frac{z(Y) u\left(\frac{1}{Y}-\frac{1}{Y-c}\right)-f(Y)\left(u \frac{1}{Y-s}-v \frac{1}{Y}\right)}{[z(Y)]^{2}}
$$

By assumption, $z(Y)>0$. Furthermore since $Y-c>0$, then $f(Y)>0$ and $\frac{1}{Y}-\frac{1}{Y-c}<0$. Also, since it is assumed that $Y-s>0$ and $u>v$, then $u \frac{1}{Y-s}-v \frac{1}{Y}>0$. This means that $\frac{\partial p^{*}}{\partial Y}<0$. 